\title{
CASE STUDY ON DEVELOPMENT OF MATHEMATICAL COMPETENCE OF FOREST SPECIALTIES STUDENTS
}

\author{
Anna Vintere, Liga Zvirgzdina \\ Latvia University of Life Sciences and Technologies, Latvia \\ anna.vintere@1lu.lv, liga.zvirgzdina@1lu.lv
}

\begin{abstract}
Mathematics studies at university develop the cognitive abilities of a person, influence studies of special subjects as well as contribute to the development of professional competence ensuring highly qualified specialists for the knowledge-based, skill and technology-intensive industries. According to the documents of OECD, the STEM fields are seen as especially important for fostering innovation and economic growth. A high level of mathematics education is necessary in order to fulfil the task of creating an innovative economy, providing long-term goals and objectives for sustainable development. Mathematics competence is important also in all aspects of sustainable development and employment prospects at the same time. From a professional point of view the mathematical skills can be considered as an absolutely necessary tool for fulfilling the tasks at job. In the light of the above considerations, it is essential to train young specialists at university to have good knowledge of mathematics, to use mathematics for problem solving in various situations of everyday and professional life. Therefore, the article analyses the dynamics of knowledge of mathematics of students of the Faculty of Forestry within the framework of the first semester, comparing the result of the diagnostic test with the final assessment of learning outcomes. In the study the authors found out the factors influencing mathematics learning at the university, which include the learning environment: emotional (mathematics learning experience and attitude) and extracurricular environment; the aims (student aims, society and employers, study course program) and the teaching / learning process. The findings are illustrated by the results of the survey of the Faculty of Forestry students of the mathematics learning experience.
\end{abstract}

Keywords: assessment of learning outcomes, diagnostic tests, mathematics, mathematical competence.

\section{Introduction}

In September 2015, the 17 Sustainable Development Goals (SDG) to be achieved over the next 15 years were adopted by the world leaders to end all forms of poverty, fight inequalities and tackle climate change, while ensuring that no one is left behind. The target of SDG 15 pronounces to "sustainably manage forests, combat desertification, halt and reverse land degradation, halt biodiversity loss" [1]. As the Latvia University of Life Sciences and Technologies prepares specialists in the Forest sciences, it is necessary to equip Forestry students with capabilities needed to take on different challenges and make decisions that consider the long-term future.

In the context of sustainable development, special attention is devoted to mathematics education and need for the mathematics knowledge and skills in a growing number of occupations. The role of mathematical competence is increasing in this context and competence-based higher education with clearly substantiated learning outcomes is a norm in higher schools across Europe.

Mathematical competence is also one of the key competences for lifelong learning [2]. Necessary knowledge in mathematics should include a knowledge of numbers, operations with them, measures and structures, mathematical presentations, etc. Mathematical literacy is also defined as students' capacity to formulate, employ and interpret mathematics in various contexts, which implies reasoning mathematically and using mathematical concepts, procedures, facts and tools in order to depict, clarify and foresee phenomena. It helps individuals see the role that mathematics plays and make healthy judgements and decisions in their everyday or broader social life [3].

From a professional point of view the mathematical skills can be considered as an absolutely necessary tool for fulfilling the tasks at job [4]. According to the UNESCO, mathematics is an instrument for sustainable development, because in mathematical activities (counting, measurement and location) people are developing ways to effectively meet their needs, indicating a clear link between people and the environment [5].

In order to contribute to the implementation of the Goal 15 of sustainable development, it is important to understand the mathematical knowledge acquired by the student by entering the Faculty of Forestry study programs and mathematical competence after compleating the course of higher mathematics at the university as well as to find out the key element of successful mathematics teaching and learning at the university and motive influencing mathematical competence building. 


\section{Materials and methods}

The development of mathematical competence of Forest specialties students is analysed by three dimensions: student's prior mathematical experience, assessment of mathematics knowledge obtained in the 1st semester after completion of higher mathematics course by the students and mathematics teachers, as well as the factors influencing mathematics learning at the university. Several pedagogical considerations have been taken into account in determining the methodology of the study.

Stephen et al. stated that mathematics diagnostic test and pre-test are useful for gaining information on students' prior knowledge and also the best predictors of future performance. The test also provides a more detailed insight into which area of mathematics the students do or do not know [6]. Diagnostic tests were also used at the Latvia University of Life Sciences and Technologies to assess students' mathematical knowledge.

The article analyses the dynamics of knowledge in mathematics of students of forest specialties in the first semester, comparing the results of the diagnostic test with the final assessment of the learning outcomes performed by the teachers, according to the evaluation procedure foreseen in the study course programs, as well as taking into account the self-assessment of students' mathematics knowledge.

To get the students' assessment of mathematics knowledge obtained in the 1st semester after completion of the higher mathematics course and to find out the factors influencing mathematics learning at the university, in the study the self-assessment method is used, which is arguably the most powerful means for tertiary education organisation to understand and improve its educational performance. According to Andrade and Valtchevs, "self-assessment is a process, during which students collect information about their own performance or progress; compare it to explicitly stated criteria, goals, or standards; and revise accordingly. The purposes of self-assessment are to identify areas of strength and weakness in one's work in order to make improvements and promote learning" [7]. For that reason, a survey of the Latvia University of Life Sciences and Technologies Forest specialties students was carried out within the framework of the research.

The questionnaire included several diagnostic blocks: information on the respondents, selfassessment of mathematics knowledge and skills, teaching mathematics at the university, mathematical learning experience, mathematics study aims, as well as suggestions what should be taught in mathematics subjects at the university and how this should be done to promote mathematics competence building. The questionnaire also included questions about the relation of mathematics with the employment. This article analyzes students' answers to questions about mathematical knowledge and skills self-assessment as well as the factors influencing mathematics learning at the university. Questionnaires included different types of questions. Respondents had to evaluate the statements by expressing their approval or rejection according to 4 steps (diagnostic blocks: "Teaching Mathematics at the University", "Mathematics knowledge") or 5 steps (Diagnostic Block: "Mathematics studies aims") Likert Scales. The questionnaire also asked other types of questions questions with the answers given and an open question: what should be taught in mathematics at the university and how it should be done to promote the development of competences necessary for sustainable development. 45 respondents (Forestry Engineering: 30 and Wood Processing: 15) participated in the survey by completing the electronic questionnaire available at http://www.iipc.lv/surv/index.php/393736/lang-lv.

Methodology for determining the factors influencing mathematical learning at the university is based on the considerations of Aleksandrs Vorobjovs, who indicates that the most important factors influencing mathematical competence are: learning environment (including physical, emotional and extracurricular), the aims (of different participants of the educational process: students' aims, society and employers' aims, aim of programme), content of teaching materials and the learning process as well as professionalism of teachers [8]. He emphasizes that balancing these factors can contribute to increasing the students' mathematical competence. In this article learning environment is analysed by emotional (students' mathematics learning experience and attitude) and extracurricular dimension.

Considering the things mentioned above, evaluation of the mathematics study aims was based on the results of the student survey, where they expressed their opinion on various statements, in the connection of the students' own mathematics goals and the aims of the study program. Students were 
also asked how, in their opinion, society and employers appreciate mathematical knowledge. In turn, the assessment of the learning process was based on assessment of four statements about teaching mathematics at the university. The factors influencing the students' math competence building are given in Table 1.

Table 1

Factors influencing students' math competence building

\begin{tabular}{|c|c|c|}
\hline Factors & Characteristics & Statements \\
\hline \multirow{2}{*}{$\begin{array}{l}\text { Learning } \\
\text { environment }\end{array}$} & Emotional & $\begin{array}{l}\text { - Mathematics has always been my favourite subject } \\
\text { - I do not like mathematics }\end{array}$ \\
\hline & Extracurricular & Refreshing course \\
\hline \multirow{3}{*}{ The aims } & Students' aims & $\begin{array}{l}\text { - The knowledge and abilities of mathematics, mathematical } \\
\text { thinking helps me to achieve more in my life } \\
\text { - Mathematics develops thinking, helps make a decision in a } \\
\text { particular situation, find new ideas }\end{array}$ \\
\hline & $\begin{array}{l}\text { Society and } \\
\text { employers }\end{array}$ & $\begin{array}{l}\text { - A person who understands mathematics will easily deal with } \\
\text { tasks that require thinking } \\
\text { - Employers highly value people who have a good } \\
\text { understanding of mathematics } \\
\text { - Studying mathematics develops logical thinking, accuracy } \\
\text { and concreteness of future specialists }\end{array}$ \\
\hline & $\begin{array}{l}\text { Aim of the } \\
\text { course }\end{array}$ & Knowledge in mathematics helped me understand other subjects \\
\hline $\begin{array}{l}\text { Teaching / } \\
\text { learning } \\
\text { process }\end{array}$ & $\begin{array}{l}\text { Teaching of } \\
\text { mathematics at } \\
\text { the university }\end{array}$ & $\begin{array}{l}\text { - Most students do not understand mathematics and try to } \\
\text { learn the laws by heart } \\
\text { - I did not understand most mathematical concepts that I } \\
\text { studied } \\
\text { - Mathematics, which I studied, could have been more } \\
\text { complicated } \\
\text { - Mathematics was an interesting and meaningful subject }\end{array}$ \\
\hline
\end{tabular}

\section{Results and discussion}

As the entrance exam in universities is long ago cancelled in Latvia, the enrolment is by the results of centralized exams at school. Centralized exam works are evaluated in percentage - from $0 \%$ to $100 \%$. Unfortunately, the student whose assessment in the centralized exam in mathematics is less than $30 \%$ and even below $20 \%$ is enrolled in the Latvia University of Life Sciences and Technologies. Apart from the assessment in the centralized exam, starting the new school year, teachers themselves assess the mathematics knowledge of their future students. Usually during the first math lesson the first-year students are given a diagnostic task. The same test for several years is fulfilled in all the so-called Baltic Agricultural Universities. The test contains 15 elementary tasks of basic and secondary school mathematics. The students have to find the correct answers from among many alternatives. They cannot use a calculator or other devices and the time allowance of the test is $45 \mathrm{~min}$.

After analysing the test results and taking into account the teachers' experience it can be concluded that the overall competence in mathematics has not increased during the latest years. Therefore, at the mathematics course at the university not only the content of the study program has to be mastered, but also the lack of knowledge gained from school. In providing students with new theoretical material not only the important definitions, formulation of theorems and their use should be followed, but also the general concepts that should have been learned at secondary school. This is a very problematic area, because the number of contact hours is limited and only for the content of the program. This requires additional efforts by teachers, because the best and most appropriate methods should be chosen to achieve the goals of the study program.

In order to analyse the dynamics of the knowledge of mathematics of the students of Forest specialties in the first semester, a comparison of the results of the diagnostic test with the final 
assessment of the learning outcomes is performed. As shown in Fig. 1, growth has been achieved. If at the beginning of higher mathematics studies $43.3 \%$ of students did not have sufficient preliminary knowledge, then at the end of the first semester only $22.2 \%$ of the students received insufficient assessment. The number of students with good knowledge also increased (from $13.3 \%$ to $24.4 \%$ ).

The questionnaire contained statements to find out how confident the students are about their mathematical knowledge. According to Aleksandrs Vorobjovs, lack of self-confidence is a very powerful obstacle to learning mathematics [8]. However, the results show that the responses of the Latvia University of Life Sciences and Technologies Forest specialty students are more optimistic than the teachers' assessment (Fig. 1).

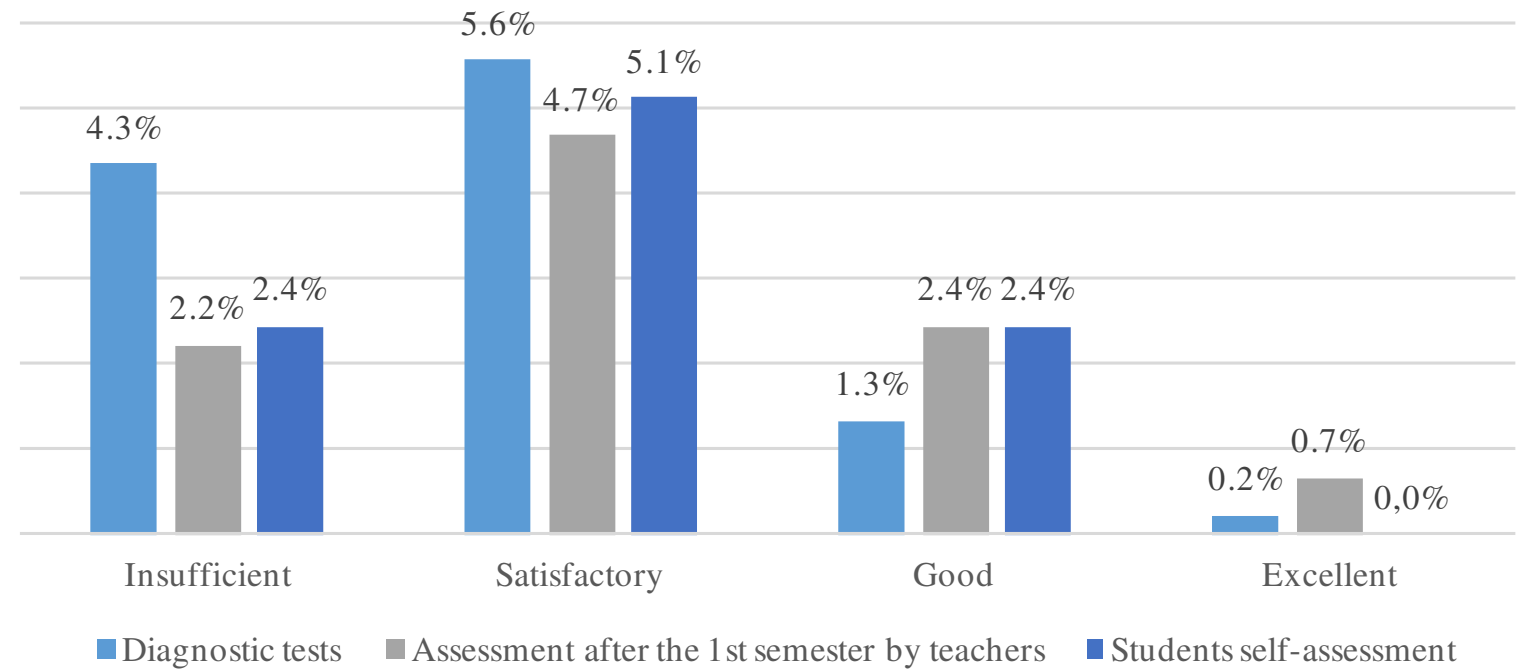

Fig. 1. Dynamics of knowledge of mathematics within framework of the first semester

Several studies show that motivation is a key element of successful teaching and learning. According to Michael Gould, there are several reasons for low learning motivation of students, e.i. the underestimation of the importance of mathematics education by the society in general, the crammed curriculum at schools and higher educational establishments, redundant content of appraisal and training materials, inability of training programs to meet the needs of students etc. [9]. In this study student mathematics learning experience and attitude are analysed as the factors that influence mathematical competence building. Several studies prove that a positive attitude to mathematics motivates learning more, making progress and better achievements [10].

About $40 \%$ of students, who have assessed their knowledge in mathematics as good, say that mathematics has always been their favourite subject. In contrast, $9 \%$ of respondents with good assessment say that they do not like mathematics. More than $60 \%$ of students, who assessed their knowledge as satisfactory, say that they do not like mathematics. It should be noted that no students have appreciated their mathematical knowledge with excellent. $44.5 \%$ of students claim that they could solve a mathematical task, if a proper description of the subject and formulas would be given. To this question just over $4 \%$ of respondents answered no.

As part of the learning environment, Aleksandrs Vorobjovs has included an extracurricular environment, other factors influencing learning in general and gaining mathematical competence in particular [8]. As stated in the "Engineering Mathematics Study Program Framework", different approaches have been adopted across Europe to address the diversity of mathematical skills and engineering cohort capabilities. In many countries mathematics support centers are being set up to provide extracurricular assistance to students, who are experiencing difficulties in mathematics. The most valuable resource provided by the mathematics support centers is the staff working with students based on one to one or in small groups. Mathematics support centers have a useful role [11].

In order to improve the quality and availability of mathematical competences, the preparatory course has been developed for the first year students of the Latvia University of Life Sciences and Technologies to strengthen their school knowledge and adapt it to the specifics of the university study 
process. Course materials are available on the Moodle e-learning platform. However, this course has not been recognized by students. It relates to the responsibility and interest of the teaching staff.

Starting the academic year 2018/2019 a repetition course of school mathematics was organized. Students, who had insufficient assessment in the diagnostic test, as well as all those, who wanted to improve their knowledge, were invited to the course. The total amount of the course is 36 academic hours, divided into three modules. This course was attended mainly by the Forest specialty students. The achievements of these students in mathematics have improved significantly, which confirms the importance of extracurricular activities in the development of competencies.

The aims are the next factor influensing the mathematical competence building emphasized by Aleksandrs Vorobjovs [8]. They include many types of aims that altogether impact the formation of mathematical competence.

- Aims of the students. This includes motivation to learn, vision of applying the curriculum later in profession or everyday life.

- Preparation of the students for inclusion and effective work in future society and in labour market.

- Aims of the education program.

Historically, mathematics has a high status. Half a century ago mathematician Willy Serve emphasized the importance of mathematics in the development of intelligence and the formation of personality, with a particular focus on logical thinking and its impact on the creation of good work skills [12]. The survey results show that $80 \%$ of the students surveyed agree or fully agree that mathematics develops thinking, helps make a decision in a particular situation, find new ideas, but almost $50 \%$ think that the knowledge and abilities of mathematics and also mathematical thinking helped them achieve more in their life. These students, who had evaluated their knowledge as insufficient, also appreciate the importance of mathematical studies. More than $70 \%$ of them are convinced that mathematics and mathematics learning develop thinking and help in decision making.

The results of the study show that only $18 \%$ of the Forest specialty students surveyed see the need for mathematics knowledge in today's labor market. It should be noted that these students, who have evaluated their mathematics knowledge as insufficient, are not aware of the role of mathematics in the labor market. Only a third of them respond positively. In Fig. 2 the Forest specialty student assessment of the aims of society and labour market is collected. The statement on the role of mathematics in training of future specialists received the highest rating.

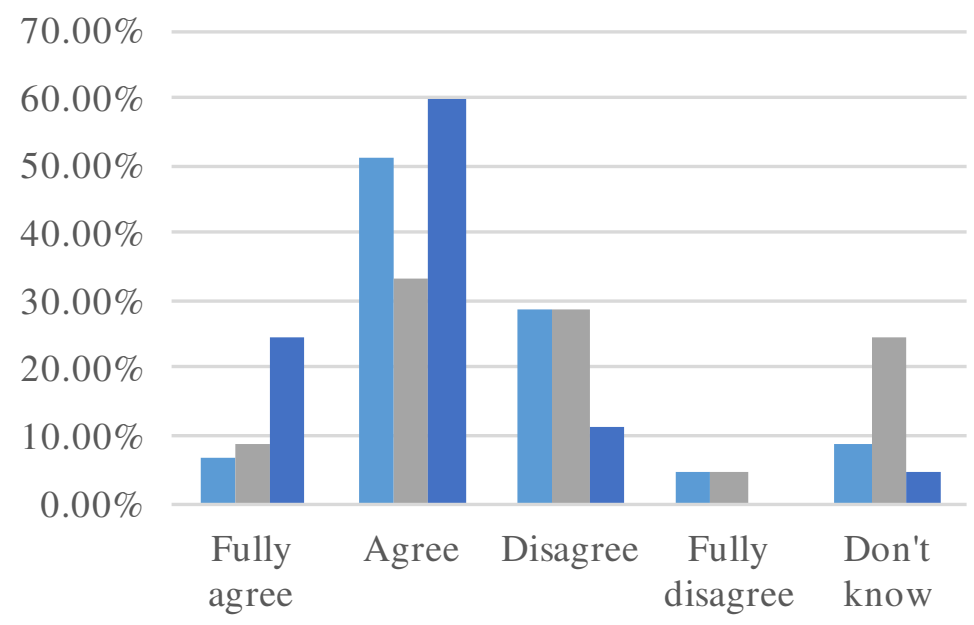

\section{A person who understands mathematics will easily deal with tasks that require thinking
- Employers highly value people who have a good understanding of mathematics

- Studying mathematics develops logical thinking, accuracy and concreteness of future specialists

Fig. 2. Assessment of aims of society and labour market by students

Aleksandrs Vorobjovs points also to the aims of the study program as one of the factors influencing mathematical competence [8]. At the Latvia University of Life Sciences and Technologies, the higher mathematics course volume is at 3 ECTS. The aim of the course: to acquire mathematical knowledge and practical skills necessary for the acquisition of other special subjects, as well as to promote mathematical thinking by looking at various mathematical applications in Forest science. Therefore, students were asked about the impact of the mathematics course on the acquisition of other 
subjects. In total, over $90 \%$ of respondents have a positive response, so proving that the mathematics study program has achieved their aims. The results of the study show that there are no significant differences in the answers of the students with different knowledge assessment.

Analysing the Forest specialties student responces on the teaching and learning process at the university, very persuasive answers were obtained to a question, if they preferred to learn "eye-to-eye" with a teacher, study independently, or better in a training group. Approximately $78 \%$ of students responded that they clearly selected an eye-to-eye study with a teacher. On the other hand, only $9 \%$ would choose own-initiative studies and $13.3 \%$ would like to study the material in a group (Fig. 3).

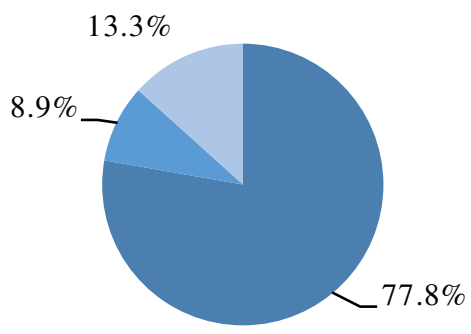

I would like to learn "eye-to-eye"
with the teacher
I choose to study independently

Fig. 3. What form of study students prefer

Studying the students' answers to a question about mathematics learning experience, highlights the relationship with the students' self-assessment. The lower the student's self-assessment, the more critical of the math course. The lower the self-assessment, the most of the math concepts the student has not understood and the math as a course of study has not been liked. The students, who have learned math at a satisfactory or good level, understand the role and necessity of math more. Such students believe that math at university could also be more complicated. More than $36 \%$ of the students with high self-assessment say that mathematics is on the list of the most pleasant courses for them, and more than $27 \%$ of students point out that in high school math could have been taught at a more difficult level (Fig. 4).
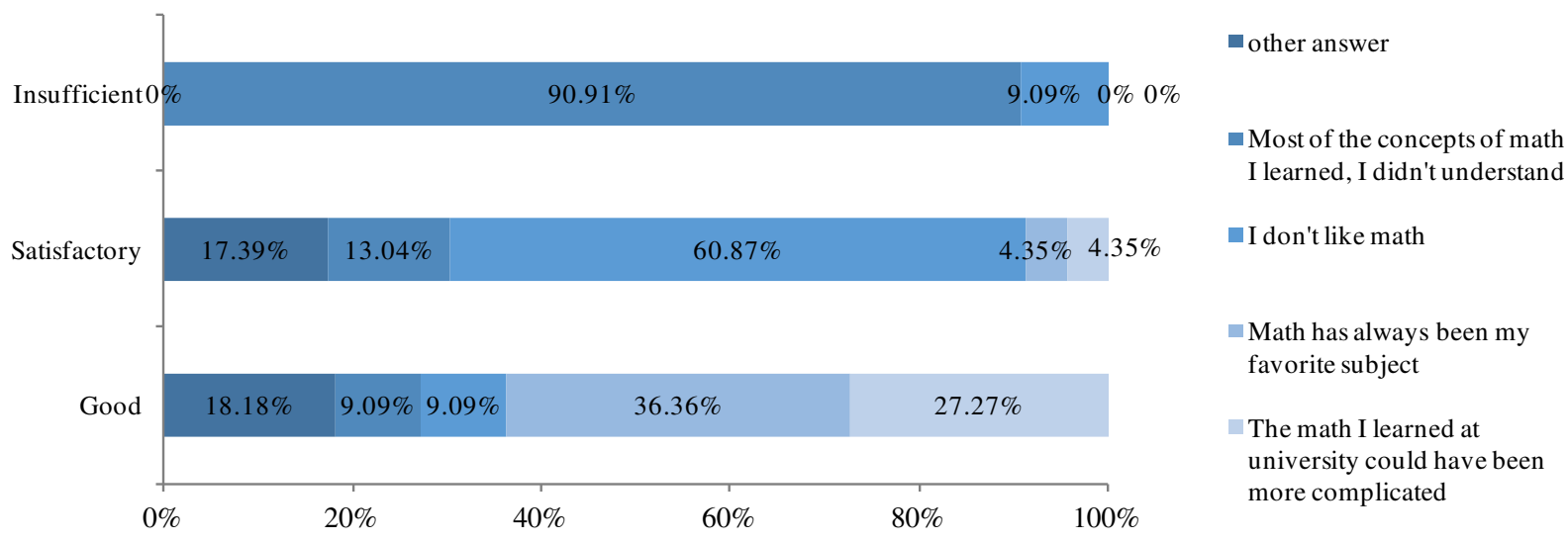

Fig. 4. Students' math learning experience according to self-assessment

Students were asked to assess the potential importance of mathematics. For example, students were asked to answer the questions - does math develop thinking, whether math helps make decisions and find new ideas.

The questions also highlight a very close relationship between the student's self-assessment and his response. The more prepared and successful in mathematics, the more positive his attitude to the math role. Nearly $55 \%$ of students with good self-assessment completely share the view that mathematics develops thinking, helps make decisions, as well as helps find new ideas. In contrast, only $9 \%$ of students with insufficient knowledge share the same view (Fig. 5). 


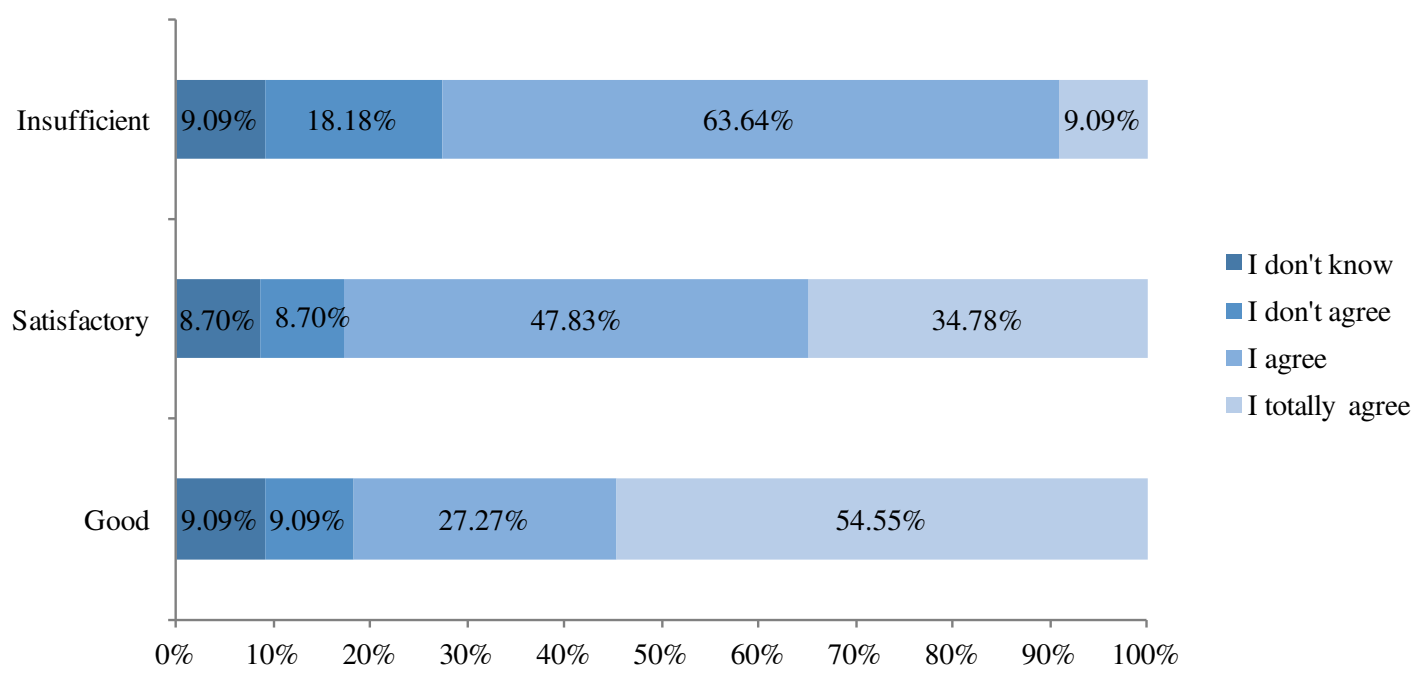

Fig. 5. Answers to question, - does Mathematics develop thinking, help make decisions and find new ideas, related with students' self-assessment

\section{Conclusions}

1. Students' competence in mathematics has not increased during the latest years.

2. Mathematics course at the university, not only the content of the study program, has to be mastered and also the lack of knowledge gained from school. The best and most appropriate methods should be chosen to achieve the goals of the study program and growth.

3. Motivation is a key element of successful teaching and learning. There are several reasons for low learning motivation of students. In the study the following factors influencing mathematics learning at the university are analysed, which include learning environment: emotional (mathematics learning experience and attitude) and extracurricular environment; the aims (student aims, society and employers' aims, study course program) and the teaching / learning process.

4. Learning environment.

- Learning experience and attitude is also considered to be an important factor in the development of mathematical competence. The study demonstrates the coherence of students' mathematical competence with self-esteem of the learning experience and attitude. The higher the self-assessment of mathematical knowledge the more positive attitude to the mathematics role.

- Extracurricular activities play an important role in the development of mathematics competencies, as the achievements of the students, who attended a repetition course of school mathematics, have improved significantly.

5. The aims.

- Students highly appreciated the role of mathematics in personal development, as $80 \%$ of students surveyed agree or fully agree that mathematics develops thinking, helps make decisions in a particular situation, find new ideas, but almost $50 \%$ believe that the knowledge and abilities of mathematics helped in their lives.

- The surveyed students are not aware of the importance of mathematics in the labor market, but highly appreciate the mathematics role in training future specialists.

- The mathematics course program at the Latvia University of Life Sciences and Technologies has achieved their aims as over $90 \%$ of respondents said that the mathematics course has helped them acquiren other subjects.

6. The survey results highlight the relationship between the answer to the question on teaching of mathematics at the university and the student's self-assessment. The lower the student's selfassessment, the more critical of the mathematics course. The lower the self-assessment, the most of the mathematical concepts the student has not understood and the mathematics as a course of study has not been liked. 


\section{Acknowledgements}

The paper was supported by the grant from the Latvia University of Life Sciences and Technologies program "Strengthening the Scientific Capacity in the Latvia University of Life Sciences and Technologies" No. Z32 entitled "Development of the didactical model for transforming mathematics studies into education for sustainable development".

\section{References}

[1] Sustainable development goals, 2015. [online] [20.02.2019]. Available at: https://www.un.org/ sustainabledevelopment/

[2] Annex to Proposal for a Council Recommendations on Key Competences for Life-long Learning. A European Reference Framework, European Comission, 2018. [online] [10.03.2019]. Available at: https://eur-lex.europa.eu/resource.html?uri = cellar:395443f6-fb6d-11e7-b8f501aa75ed71a1.0001.02/DOC_2\&format = PDF

[3] PISA 2015 Results (Volume I): Excellence and Equity in Education, PISA, OECD Publishing, Paris, 2017. [online] [25.03.2019]. Available at: http://dx.doi.org/10.1787/9789264266490-en

[4] Education at a Glance 2017: OECD Indicators, OECD Publishing, Paris. [online] [20.02.2019]. Available at: http://dx.doi.org/10.1787/eag-2017-en.

[5] Textbooks for Sustainable Development. A Guide to Embedding. UNESCO MGIEP, 186 p. [online] [3.03.2019]. Available at: http://unesdoc.unesco.org/images/0025/002599/259932e.pdf

[6] Lee S., Harrison M., Pell G., Robison C.L. Predicting performance of first year engineering students and the importance of assessment tools therein. Engineering Education, 3(1), 2008, pp. 44-51.

[7] Andrade H., Valtcheva, A. Promoting learning and achievement through self-assessment. Theory Into Practice, 48, 2009, pp. 12-19.

[8] Vorobjovs A. Adolescents' Mathematical Competence Formation Influencing Factors. In V. Dislere (Ed.), The Proceedings of the International Scientific Conference Rural Environment. Education. Personality (REEP), 10. Jelgava: LLU TF, 2107, pp. 315-320.

[9] Gould M. GIScience grand challenges: How can research and technology in this field address big - picture problems? ArcUser, 13(4), 2010, pp. 64-65. [online] [18.03.2019] Available at: http://www.esri.com/news/arcuser/1010/files/geochallenges.pdf

[10] Kislenko K. Grevholm B., Lepik M. Mathematics is important but Boring. Students'beliefs and attitudes towards mathematics. 2007. [online] [20.03.2019] Available at: http://www.divaportal.org/smash/get/diva2:1005253/FULLTEXT01.pdf

[11] Alpers B. (Eds.) A Framework for Mathematics Curricula in Engineering. Brussels: European Society for Engineering Education, 2013.

[12] Serve, V. Teaching mathematics in secondary schools. Mathematical Education, Vol. 1, 1957, pp. 22-32. (In Russian). 